\title{
Teaching the scientific style of speech online
}

\author{
Olga Nikolenko $^{1^{*}}$ and Tatiana Chernykh ${ }^{1}$ \\ ${ }^{1}$ Don State Technical University, 344003, Gagarin sq., 1, Rostov-on-Don, Russia
}

\begin{abstract}
The article reveals the problem of distance learning that is relevant for the modern methodology of Russian as a foreign language and proves that its technology requires maximum intellectual and emotional enrichment of each hour of study time, a significantly higher level of pedagogical understanding of activities on the part of the teacher, the creation and implementation of various concepts of professional personality development. in the process of studying. The authors put forward the idea that a clear, consistent algorithmization of user actions, embedded in the computer program, through which the student and the teacher are connected, contributes to a positive solution to this problem. Only these actions lead the foreigner step by step to the final goal of learning, offering help at the right time, registering the correct answer and mistakes, emotionally encouraging him with remarks and sending him to the bank of reference material, to various kinds of comments.
\end{abstract}

\section{Introduction}

Teaching Russian as a foreign language is a continuous pedagogical system that is based on didactic principles that take into account the systematic development of communication skills and mastery of a specialty. This presupposes strengthening of professional, social, personal interest in mastering a foreign language through the use of all the possibilities of the educational process. The global epidemiological situation, forcing foreigners to receive education in our country remotely, makes it somewhat difficult to move towards the designated goals.

The introduction of distance learning in Russia is a new area of educational and social practice, including the comprehensive automation of educational work. Observations show that at the moment the pace of technical development of computers is significantly ahead of the level of their psycho-pedagogical comprehension, which forces the methodology of any discipline to engage in an intensive search for its methodological improvement in the indicated direction. The widespread introduction of distance learning into the educational process is still hampered by the computer illiteracy of teachers. In this regard, the overwhelming majority of both Russian and foreign universities create platforms for the exchange of experience when creating control and training programs or for holding scientific and methodological conferences highlighting methodological techniques that contribute to solving the intensification and individualization of the educational process, its

\footnotetext{
* Corresponding author: olganikolenko15011977@,gmail.com
} 
adaptation to the non-contact (distance) training, individual characteristics of students, providing expanded opportunities for their independent work

\section{Materials and methods}

As a linguistic material for the proposed study, highly specialized texts of a technical orientation (mainly lectures on mechanical engineering), subjected to the methods of linguistic observation and description (when determining the status of emphatic models), comparative and contextual analysis (when identifying their functional features), the method of continuous sampling and statistical calculation (for the presentation of a quantitative characteristic of the indicated syntaxemes).

\section{Results}

In the practice and methodology of teaching Russian speech to foreign students, the fundamental is the provision that the development of speech skills and abilities both in the social and everyday life and in the professional sphere should be brought to automatism based on the formation of the corresponding stereotypes: articulatory, grammatical, lexical, phrasal and syntactic.

When mastering the lexical and grammatical means of the language, not only word formation skills are formed, but also word usage skills, which is of great importance in the communicative process in speech perception and speech production $[12,13]$.

Communication is a suggestive factor in learning, since it correlates with the category of intensification through the category of intensity: in accordance with the provisions of social psychology, the need for verbal communication is an organic need of a person as a social being, which is due to his very biological nature $[14,15]$.

The specificity of preparatory faculties is that the "zero knowledge of the language", with which a foreigner begins his studies, creates difficulties associated with the language barrier, overcoming which causes a great strain of mental and physical strength, volitional efforts, a major restructuring of the entire regime of life and study. The solution to these problems presupposes the rational organization of educational material, the availability of a textbook and (or) a mass educational online course (MEOC) (mainly for distance learning), adequate to the tasks and content of training, and their methodologically correct use, the maximum use of methodological techniques that make the educational process more effective, training of training personnel and the creation of the credibility of the training regime. Only under these conditions can learning be intensified and communicatively directed.

The use of computer technologies to improve the lexical and grammatical skills of distance learning foreigners at the preparatory faculty seems to us the most acceptable and effective way to intensify the educational process. For this purpose, software is required that must match the technical and didactic capabilities of the computer. It should be based on the methodological concept of the formation of skills and abilities as a unity of automatism and awareness, fixity and mobility. The script of the programs should consist of doses of lexical and grammatical educational material; predicting student activities; reactions (answers displayed on the screen depending on the answers or actions of the student); evaluating his actions; a list of statistical data that are registered and accumulated in the computer memory; conditions and order of transition from one training dose to another. 
When developing a program scenario, it is also necessary to determine the dose and text material, taking into account the stage and purpose of training, the initial and final level of formation of the foreign student's speech skills and abilities.

As already mentioned, the technology of distance learning Russian as a foreign language requires the creation and implementation of rich and varied methods, an important basis for which is the development of MEOCs in the software system, which includes minimized material, organized according to the principle of complexity and concentricity, contributing to the expansion and deepening of the initial knowledge, for example, verbal operations for recognition, understanding, differentiation and classification of the presented vocabulary.

Table 1. Types of tasks.

\begin{tabular}{|l|l|}
\hline \multicolumn{1}{|c|}{ purpose of the assignment } & \multicolumn{1}{c|}{ filing form } \\
\hline $\begin{array}{l}\text { The task to determine the knowledge of vocabulary in a } \\
\text { denotative meaning }\end{array}$ & $\begin{array}{l}\text { Mark the word with a plus sign, which can be } \\
\text { inserted instead of dots in this sentence. }\end{array}$ \\
\hline $\begin{array}{l}\text { The task to determine the knowledge of the lexical } \\
\text { combination of words, due to the lexical background of } \\
\text { the linguistic unit }\end{array}$ & $\begin{array}{l}\text { Mark the word with a "plus" sign that can be } \\
\text { combined with the selected one. }\end{array}$ \\
\hline $\begin{array}{l}\text { The task to determine the ability to combine words on a } \\
\text { common semantic basis }\end{array}$ & $\begin{array}{l}\text { Exclude from each line a word that is not similar in } \\
\text { meaning to the others. }\end{array}$ \\
\hline $\begin{array}{l}\text { Tasks to determine the ability to correctly build phrases } \\
\text { due to the nature, for example, of a scientific field of } \\
\text { knowledge }\end{array}$ & Write a word that can be combined with the rest. \\
\hline $\begin{array}{l}\text { Assignment for the definition of knowledge of a } \\
\text { professional nature }\end{array}$ & $\begin{array}{l}\text { a) Mark the term, which corresponds to this } \\
\text { characteristic; b) Define the following terms. }\end{array}$ \\
\hline $\begin{array}{l}\text { Assignment for determining knowledge of the lexical } \\
\text { background with active possession of a word }\end{array}$ & $\begin{array}{l}\text { Write (tell) what you know about (steel, cement, } \\
\text { aluminum ...) }\end{array}$ \\
\hline
\end{tabular}

Depending on the degree of formation of lexical skills and the level of knowledge of the lexical meaning of a word, tasks can be offered for the semantisation of a keyword, differentiation or classification of words, for building your own logical statement, substantiating the stated position, for comparing phenomena and objects, characterizing phenomena and objects through the prism of I. -position, etc.

The presentation of the material can also take place through authentic game situations or typical games that form lexical and grammatical skills. These can be, for example, games that teach foreign students to use Russian verbs of movement or games associated with the development of dialogical speech in standard situations. Numerous studies at the Department of Russian as a Foreign Language of the Don State Technical University testify to the effectiveness of the game method of teaching, since this contributes to the creation of a favorable psychological climate, which makes it possible to increase the effectiveness of teaching; increasing the level of assimilation of theoretical material; mobilization of knowledge, experience and imagination of the student, the development of his linguistic guess; transformation of knowledge into professional skills.

Naturally, in a non-contact environment, teaching foreign students the language of the specialty: reading, listening, taking notes of scientific literature, as well as independent production of a text of a professional orientation, causes special difficulties. Due to the fact that teaching the language of a specialty should be based on the professional and cognitive side of mental activity, it is very important to select educational and scientific texts, a system of tasks for the formation of monologue speech skills, forms of verification and control.

At the first stage of studying the scientific style of speech by foreigners, future engineers, the primary foundations of the skills of oral monologue are laid on the material of introductory classes in mathematics, physics, chemistry, etc., where the task is to reproduce the read scientific microtexts based on drawings, diagrams or a plan proposed by 
the teacher text, because the ability to reproduce the information contained in the text is an important condition on the way to achieving the ultimate goal - building your own utterance. In order to accomplish this task, work is being carried out, primarily related to overcoming language difficulties:

1. The transfer of content by the teacher and fixation of what is reported by the students.

2. Implementing a reverse-directed process for communicating content perceived by students.

3. Clarification of certain elements of the content, not understood by foreigners in the teacher's message, or missed by him upon presentation.

This type of exercise is implemented in the framework of the following professional speech situations: definition of an object, structure of an object, characteristics of an object in terms of composition, qualitative characteristics of an object, characteristics of an object in terms of properties and classification of objects. The system of exercises includes tasks for drawing up general and particular questions and answers to them, on the periphery of sentences, replacing statements with synonymous phrases, etc. At the first stage, students develop the ability to understand the content of a coherent text, navigate in its general structure, and reproduce the content of these paragraphs from memory.

At the second stage, the main place in teaching monologue speech within the framework of the Scientific style of speech is given to exercises aimed at developing the ability to curtail someone else's utterance and develop one's own.

A series of exercises is aimed at developing the ability to compress the proposed text, including tasks to determine the topic of the text, the number of subtopics developing in each topic; highlighting the main, concretizing and redundant information. For this purpose, foreigners are offered tasks of the following type:

1. Trace the logical sequence in the presentation of the material.

2. Find sentences that signal the start of a new subtopic.

3. Trace the correspondence of the sequence of nominative sentences logic of text presentation.

4. Arrange the sentences extracted from the text in a given sequence.

5. Retell the text not in text, but in a logical sequence, etc.

Due to the fact that at the first two stages of systematic work on teaching coherent monologue speech (reproduction or collapse of someone else's utterance), speech reproduction was provided, the third stage seems to be the most important and difficult, during which foreigners develop skills for generating and deploying their own utterances.

The achievement of this goal is facilitated by a system of tasks with their gradual complication (extended answer to a question, logical conclusion of a statement, expanding individual paragraphs of a text, restoring a text based on plot-based sentences, retelling a similar, specially composed text read or listened to by students; independent message on the topic, related to the topic of the studied text.

\section{Discussion}

The question of choosing a teaching methodology for any discipline (and Russian as a foreign language, in particular) in the context of distance education is currently particularly relevant. In this regard, almost all educational institutions create their platforms for the implementation of educational programs using computational linguodidactics, which opens up excellent prospects for optimizing the formation and development of the communicative-speech competence of foreign students, as well as supporting and promoting the Russian language in the world [8]. All this puts at the forefront the discussion of problems related to the insufficient conceptual development of information 
computer technologies. The first scientists-Methodists to raise this issue were E.G. Borisova, A.N. Bogomolov, A.A. Andreeva, O. I. Rudenko-Morgun [1, 3, 5] and others. In their writings, they discussed the possibility of using distance systems in teaching Russian as a foreign language. Innovations in the use of computer technologies for linguodidactic purposes are presented in the works of G.N. Shamonina, O. I. Meshcheryakova and L.V. Moskovkin, offering a communicative methodology for teaching RFL in a simulator of a language environment $[10,11]$. The linguo-methodological point of view on the indicated problem is adhered to by V.G. Kostomarov, E.M. Vereshchagin, A.L. Nazarenko, O.D. Mitrofanova, A.N. Shchukin, I.A. Orekhova [7, 9, 11], as well as O.A. Velikoselsky [6], who described the principles and specifics of creating educational electronic manuals. However, a comprehensive study of the specifics of distance learning in an active language environment based on the technologies of virtual worlds does not yet exist.

\section{Conclusion}

The analysis of modern educational in terms of distance learning Russian as a foreign language allows us to conclude that its methodology needs to create MEOCs, interactive learning environments, which are designed as a means of accumulating the experience of social interactions, objectifying social strategies of personality development, pushing the scope of individual capabilities not only students, but also teachers; only on this basis, I think, it is possible to effectively form and automate speech skills and abilities in teaching Russian to foreign students. The creation within the framework of MEOCs of tasks aimed at the system of work on the formation of oral monologue skills of professional and everyday topics, taking into account the educational and cognitive communication needs of students, is a necessary basis for the development of more complex skills of spontaneous monologue speech at an advanced stage of teaching the Russian language, providing training for foreigners to enter into communication in an authentic language environment.

\section{References}

1. V. Zusman, Literary , 2, 3-29 (2013)

2. G.Ferguson, C.Perez-Llantada, R. Pio, English as an International Language of Scientific Publication: A Study of Attitudes World Englishes. 30, 41-59 (2011) DOI: 10.1111/j.1467-971X.2010.01656.x

3. V. Zinatullin, E. Chibisova, Questions of theory and practice, 2(4) 129-133 (2009)

4. A.N. Bogomolov, GosIR named after A.S. Pushkin (2013)

5. N. Chater, S.M. McCauley, M.H. Christiansen, Journal of Memory and Language, 89, 244-254 (2016)

6. M.Adam, A Handbook of Functional Sentence Perspective (FSP in Theory and Practice), Pejiagpgicka fakulta Masarykoya uniyerzita, 98 (2017)

7. V.A. Zhiltsov, E.N. Pavlicheva, Information resources of Russia, 1, (2015)

8. O.I. Meshcheryakova, Distance and virtual learning (2013)

9. A.L. Nazarenko, Information and communication technologies in linguodidactics: distance learning. Publishing house of Moscow University (2013)

10. O.V. Nikolenko, A.V. Belozerova, N.V. Sumina, E.Y. Shapovalova, Parcelled phrases in the aspect of business communication "Breakthrough Technologies and Communications in Industry". International Scientific Practical Conference (2018)

11. O.V. Nikolenko, O.E. Zakharchuk, L.D. Babakova, B.N. Morenko, The 'I' of the 
author and its persuasive function (as exemplified by the complex sentence with homogeneously collateral sub clauses). The 9-th International Scientific and Practical Conference "Current issues of linguistics and didactics: The interdisciplinary approach in humanities" (CILDIAH) (2019)

12. A.N. Shchukin. Methods of teaching Russian as a foreign language (2010)

13. B.Strickland, M.Fisher, F.Keil, J.Knobe Syntax and intentionality: An automatic link between language and theory-of-mind, Cognition, 133(1), 249-261 (2014)

14. V. Zinatullin, E. Chibisova, Philological sciences. Questions of theory and practice, 2(4), 129-133 (2010)

15. E. Borisova, Questions of linguistics, 2, 113-121 (2011)

16. O.V. Zuga, S.D. Zlivko, In the world of scientific discovery (2014) 